\title{
Sertraline and Hyperpigmentation: A Case Report
}

To the Editor:

May 8, 2007

Sertraline is a selective serotonin reuptake inhibitor (SSRI) that affects the serotnin neurotransmitter. Reported side effects of SSRIs are mostly mild and the most frequent are headache, vomiting, insomnia, and tremor. Reported skin reactions to SSRIs are mainly rash. There are some reports of hyperpigmentation with flouvoxamine and paroxetine. There is only one case report of hyperpigmentation and sertraline where the exact time of onset, its localization, and drug dosage were not reported. ${ }^{1}$

\section{CASE REPORT}

F.M. is a 56-year-old woman referred due to depression, irritability, insomnia, hopelessness, agitation, fatigue, helplessness, and decreased level of function from $\sim 3$ years ago. She has not taken any antidepressant during the last 6 months prior to referring to the psychiatrist. She was diagnosed with major depressive disorder as per Diagnostic and Statistical Manual of Mental Disorders, Fourth Edition diagnostic criteria.

Sertraline was intiaited at $25 \mathrm{mg} / \mathrm{day}$ and titrated to $100 \mathrm{mg}$ after 28 days. She took it regularly and her depression was significantly improved in follow up visits. Three months later, there was a complaint regarding gray-brown hyperpigmentation that was limited only to her forehead. The patient had no history of similar pigmentation in the past. Although it was recommended to change her medication, she refused and continued taking it for 7 months. Three months after discontinuation, her hyperpigmentation was persistent. She was visited by an internal medicine specialist and there was no positive finding in the results of systematic med- ical examination and laboratory examination such as blood level of potassium, blood level of sodium, ratio of white blood cells, fașting blood sugar, thyroid function tests, and electrocardiograph. There was not any evidence of Addison's disease. There is no photograph of the lesion.

\section{CONCLUSION}

This report may potentiate the possible relationship between sertraline and hyperpigmentation. Melanin pigmentation disturbance was reported to be related to changes in color of skin. $\alpha$-melanocyte stimulating hormone ( $\alpha$-MSH) production is related to dopamine and serotonin. $\alpha$-MSH stimulates tyrosinase and melanin synthesis may be related to hyperpigmentation. However, there are some limitations that should be considered leg, skin biopsy was not done, because the patient refused).

Sincerely,

Ahmad Ghanizadeh, MD

\section{REFERENCE}

1. Puijenbroek EPV, Grootheest ACV, Diemont WL. Hyperpigmentation associated with the use of serotonin reuptake inhibitors. Pharmacoepidemiology and Drug Safety. 2002;11(S2):264-265.

Dr. Ghanizadeh is assistant professor of Child and Adolescent Psychiatry at Shiraz University of Medical Sciences at Hafez Hospital in Iran.

Disclosure: Dr. Ghanizadeh does not have an affiliation witth or financial interest in any organization that might pose a conflict of interest.

Please send letters to the editor to: CNS Spectrums, c/o Eric Hollander, MD, 333 Hudson St., 7th Floor, New York, NY 10013; E-mail: vi@mblcommunications.com. 


\section{Optimizing Antipsychotic Efficacy and Tolerability}

\section{Learning Objectives}

- Review the unmet needs in the diagnosis and treatment of schizophrenia and bipolar disorder and discuss the medical comorbidities affecting patients with mental illness

- Examine treatment issues surrounding atypical antipsychotics, including optimizing efficacy while minimizing metabolic risks

\section{Live Symposia}

March 9 - Chicago, IL March 23 - San Francisco, CA March $24 \cdot$ Houston, TX April 20 - New York, NY April 28 - Phoenix, AZ May 4 - Boston, MA May 5 - Washington, DC June 1 - Dearborn, MI June 30 - St. Louis, MO TBD - Pittsburgh, PA

Teleconferences available April 9 - June 7

Faculty

Peter F. Buckley, MD

Professor and Chairman

Department of Psychiatry and Behavioral Health

Medical College of Georgia

Augusta, GA

David G. Folks, MD

Professor of Psychiatry

University of Nebraska College of Medicine

Omaha, NE

Chief of Psychiatry and Behavioral Health Services

Maine General Medical Center

Augusta and Waterville, ME

\section{Jonathan M. Meyer, MD}

Assistant Professor of Psychiatry in Residence

Department of Psychiatry

University of California, San Diego

San Diego, CA

\section{Vivek Singh, MD}

Assistant Professor

Department of Psychiatry

University of Texas Health Science Center

San Antonio, TX

\section{Managing Bipolar Disorder in Primary Care: A Case-Based Approach}

\section{Live Symposia}

April 27 - Boise, ID

May 12 - San Antonio, TX

June 23 - Tulsa, OK

June 29 - Little Rock, AR

TBD • Atlanta, GA

Teleconferences available April 12 - June 19
For more information or to register, go to www.clininsights.com or call 8007501878

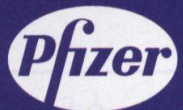

\section{Learning Objectives}

- Improve skills for the differential diagnosis of bipolar mixed and manic episodes from unipolar depression

- Discuss the medical comorbidities affecting patients with bipolar disorder

- Examine treatment issues surrounding atypical antipsychotics, including optimizing efficacy while minimizing metabolic risks

Faculty

Larry Culpepper, MD, MPH

Professor of Family Medicine \& Founding Chairman

Department of Family Medicine

Boston University School of Medicine

Boston, MA

Daniel E. Diamond, MD, FAAFP

Clinical Assistant Professor

University of Washington School of Medicine Seattle, WA

Andrea Matthew Fagiolini, MD

Associate Professor of Psychiatry Medical Director, Bipolar Disorder Center University of Pittsburgh School of Medicine Western Psychiatric Institute and Clinic Pittsburgh, PA

\section{S. Nassir Ghaemi, MD, MPH}

Associate Professor of Psychiatry and Public Health Director, Bipolar Disorder Research Program Emory University Atlanta, CA

\section{Neil S. Kaye, MD, DFAPA}

Clinical Assistant Professor of Family Medicine Clinical Assistant Professor of Psychiatry and Human Behavior Jefferson Medical College Philadelphia, PA

Peter I. Knoblich, MD

Staff Physician

Sutter Roseville Hospital

Roseville, CA

Private Practice

Northern California 